\title{
Communication: Linking all the Pieces: The 7AIQ Method
}

\author{
Paul R. Friesen \\ Department of Practical English, Korea Nazarene University, Republic of South Korea
}

Copyright $(2017$ by authors, all rights reserved. Authors agree that this article remains permanently open access under the terms of the Creative Commons Attribution License 4.0 International License

\begin{abstract}
One of the challenges of ESL is to help students to speak L2 using their own words in a more meaningful way. In Korea, a focus on specific skills related to the TOEIC test often leaves students with memorized answers. The limitation of rote memory learning and separated skills leads to minimal communication and comprehension of ideas. Korean teachers have been tasked with two of the four elements (reading and listening), while the foreigners are laden with the other two (speaking and writing). The 7AIQ method is a response to the communication by students' learning through a "segregated" system. This process is focused on asking students to think about "What do I want to communicate?" for each part of the dialogue by using at least seven words for each answer and question while adding information. The study was a review of the premise that students would fare better if they focused on longer communication segments. Students become frustrated when they speak in .The participants were students enrolled in a practical University English program. The students worked in pairs, resulting in the evaluation as a final test. There was no questionnaire conducted at this point. The initial reaction was that it was harder for the lower skilled students and smoother and more enjoyable for those who had achieved a higher skill level.
\end{abstract}

Keywords Conversation, Rhythm, 7AIQ, English, Segregated, Integrated

\section{Methodology}

The students in the class were unleveled. Students were tasked, in the beginning, by writing about a topic covered in the book. Initial instruction was given to reflect what the instructor was looking for the 7AIQ.

Defining 7AIQ was described as not opening a conversation with the primary "Hi! How are you?" Rather a seven word sentence comprised of a statement. [Appendix 1] This would be similar to "I hate the hot weather in summer."
Information follows the statement. One example could be "I want to go to a mountain where it is cool." The conclusion of this person's conversation would be a question. The information encourages a response to a topic of interest, "Where do you like to go when it is hot in summer?"

A response would have the same pattern of 7AIQ. The answer to the question would use similar words from the question. It can be asked to affirm that the communication was correct while adding personal information.

Each segment has seven or more words with sentence breaks during the speaking. Given the sample, the task of students was to rewrite their dialogue to reflect the 7AIQ pattern.

Answer - When it is hot in summer, I like to go to the beach.

Information - I take a large umbrella and a cooler. I like to play beach soccer with some friends.

Question - Who would you like to go to the mountain with on the weekend? The selected students would have their dialogue projected on the screen to read and script correction. During the class, students would use a wireless keyboard/mouse to make corrections to grammar, communication sequence changes, punctuation, and so on. Other students would listen and be able to make similar corrections to their team's dialogue.

Students first read their script aloud at the beginning and then their corrected texts. This pre and post reading allowed students to compare and realize the differences in their skills when they used the 7AIQ method.

As the dialogues became lengthier on paper, the time allotted for speaking also became longer. The corrections moved from writing to intonation, rhythm, and meaningful communication. The resulting dialogue was not always the emotional dynamic hoped for, but the lack of stress in speaking, the communication of ideas demonstrating longer and fuller ideas.

Integrating whole ideas into a dialogue while teaching grammar, syntax, movement, and expression allowed students to demonstrate their skill and strengthen the weaknesses through correction. This correction is dissimilar to the standard teaching which segments the students' learning with limited or no integration. 


\section{Strategies}

Oxford [1] pushes the idea that strategies of learning are keys to learning. Chamot and El-Dinary [2] refer to good language learners [3] "to be skillful in monitoring and to adapt different strategies. They demonstrate flexibility in using strategies to accomplish different language learning tasks. On the other hand, weak learners cling to ineffective policies that hinder successful language learning. They focus too much on details, whereas active students concentrate on the task as a whole."

What needs to be considered significant in conversation strategies, Dubberly and Pengaro [4] argue that "We talk all the time, but we're usually not aware of the when communication works and when it doesn't, and how to improve it." In their discussion of Shannon's Model (Appendix 3), they see the limits or lack of strategies available. Shannon's Model reflects what the students in South Korea use for a base. The standard teaching method in Korea has been segregating ESL learning into sections. Students demonstrated this in their first writing (Appendix 2). The strategy for creating a text from textbooks used in previous learning is the basis for learning which has one line of English in each speaker's utterance. The contrary to Shannon's Model from Dubberly and Pangaro, is the lack of new ideas or sequences required for any movement in the communication of ideas [5]. Dubberly suggests that conversation happens when a channel opens.

In the 7AIQ Model, students are encouraged to draw upon "I" or Information and push into initializing a communication and expanding it by sequencing their ideas. In Friesen's book "Making Conversation Work for You," Friesen [6] suggests that building from previously learned vocabulary in four distinct areas: Time, Action, Motion, and Emotion are the cores of constructing a better communication strategy or model. The four specific areas were used by students to activate students to try and achieve successful choices of plans. These choices, in turn, became the baseline for their learning of a new strategy.

The next step is that students must have an impetus to respond in committing to a conversation [7]. Just information is not enough. Dubberly and Pangaro suggest that this is a valuation of the information with a response that engages to a continuance of the dialogue.

Encouraging a commitment to continue would be Question in the 7AIQ Model. The 7AIQ Model suggests participant offering a value derived from Information and adding a question to elicit a response. Using seven words in each of the AIQ, participants add value, change direction, and reiterate what they have heard for confirmation of the communication put forward.

After confirming the initial value, adding meaning through reconstruction or repetition and expansion of the idea are essential. The evolution of the conversation continues through agreements followed by actions.

"Effective conversation" would be defined as ending with an action or transaction [8]. This endpoint would not be a part of many conversations. Successful communications for many students would be able to engage, confirm, and agree to a series of ten or more interactions. The goal of 7AIQ is to lessen the fear through developing a strategy of communicating whole ideas. Seven words make the information enough for conversation participants to decide to commit, change the topic or direction, or exit.

\section{7AIQ Strategies}

From the outset, the student has the freedom to communicate using previously learned ideas, vocabulary, and grammatical structure. The anticipation is that the students will demonstrate short grammatically correct sentences which will not elicit a hoped for response. Questions like "Where are you from?" are common in ESL books but open the door to misinterpretation. Changing the question to "What country are you from?" will elicit the response that the person is looking for. The misunderstanding of the problem is minimal because it is more precise and opens the door to discussion about different perceptions of the country.

Better questions will result in better answers followed by better communication and confidence. Teaching vocabulary or grammar, though separate ideas, is integrated into the learning cycle through reconstruction and challenge to what the student wants to communicate. Challenging students to ask themselves what they expect for a response and building their questions to fit their expectations into a more critical thinking moment. Grammar and vocabulary are necessary for communication, but adding them after the initial output allows them to understand the needed changes.

The strategy behind adding information is to encourage the receiver to respond with similar information. This approach gives the conversation depth and direction. Information also expands the initial question or answer demonstrating an understanding of the question or flow of the topic. Information personalizes the problem creating an emotional tie to the conversation. This connection does not imply a friendship, but those emotions, once tweaked, will help keep the conversation moving forward. Information is often assumed, and therefore misinformation is collected raising the stress level. This affirmation is important to the ongoing flow of communication.

The strategy behind the longer answers is that a repetition lessens the miscommunication. Repeating the question in the answer is taught but many ties ignored in the quest to make everything short. Culture encourages a "The shorter, the better" view, whereas the best communication is often through longer ideas. Longer answers integrate the question allowing the student more time to develop their responses.

Starting with the student's concepts and ideas develops the confidence to speak. The lack of criticism will lessen the fear of failure. Inserting vocabulary to use allows the teacher to 
use segregated learning sessions to build better communication objectives. The integration of ideas to produce a longer dialogue gives the students experience and a stronger resolve that developing a few strategies will enhance their success.

\section{Conclusions}

The classes used were small and the time was short. With mixed level classes in the study, the satisfaction level was also mixed. Students are in one class for one semester. The length of time the students worked on the method limits the results for long-term change to occur. To instill a strategy is the primary goal. Students will have been challenged to understand why they do not get the desired response and they will be given a strategy to use. Building on what the student has already learned integrates all the elements of language learning in a more active learning environment [9]. A longer more detailed study would be required to analyze the long-term effects of the methodology in communication.

Other studies are suggested to develop a strategy of listening for Koreans. Koreans often do not hear the beginning word in a sentence responding to the last word or idea communicated. The 7AIQ system does help with this somewhat but would need more controlled study.

\section{Appendix 1}

\section{A demonstration of the 7AIQ model}

\section{Sample 1. Weather}

Bros: I hate hot weather in the summer. I want to go to a mountain where it is cool. Where do you like to go when it is hot in the summer?

Bao: When it is hot in summer, I like to go to the beach. I take a large umbrella and a cooler. , I like to play beach soccer with some friends. Who do you like to go to the mountain with?

\section{Sample 2. Vacation}

Julie: I'm getting burned out and I need a vacation. I think a trip to Bali would be a great idea. Where would you like to go on a dream vacation Judy?

Judy: On a dream vacation, I would like to go to Japan.
The variety of desserts makes my mouth water. What kinds of desserts are your favorites?

\section{Appendix 2}

\section{A sample of initial dialogue writing by a student}

Employee: Welcome! Excuse me, may I can help you and is there something you're looking for?

Customer: Thanks for your help. First I'm looking for a coffee machine.

Employee: How about brew king?

Customer: What are the advantages?

Employee: It is convenient and does not easily break.

Customer: It's good. How much is it??

Employee: $150 \$$.

Customer: It's too expensive, do you have any other machine?

Employee: I have morning star and cup star. Morning star is small and practical; cup star is most popular in stores.

Customer: How much is the cup star?

Employee: Cup star is $80 \$$

Customer: So good. I'll take this.

Employee: How would you like to pay for it?

Customer: I'll pay in cash. I have a discount coupon. Can I use it?

Employee: Sure!

Customer: What is the discount rate?

Employee: This is a $10 \%$ discount coupon. You only need to pay $72 \$$.

Customer: Oh very nice. Here's the money.

Employee: Thank you. We expect your next visit.

\section{Appendix 3}

\section{Shannon's Model of Communication:}

A message flows from an information source through a transmitter that encodes a signal.

The communication channel, shown as the tiny square box subject to noise,

Conveys the signal to a receiver, which decodes the signal into a message that is delivered to a destination. 


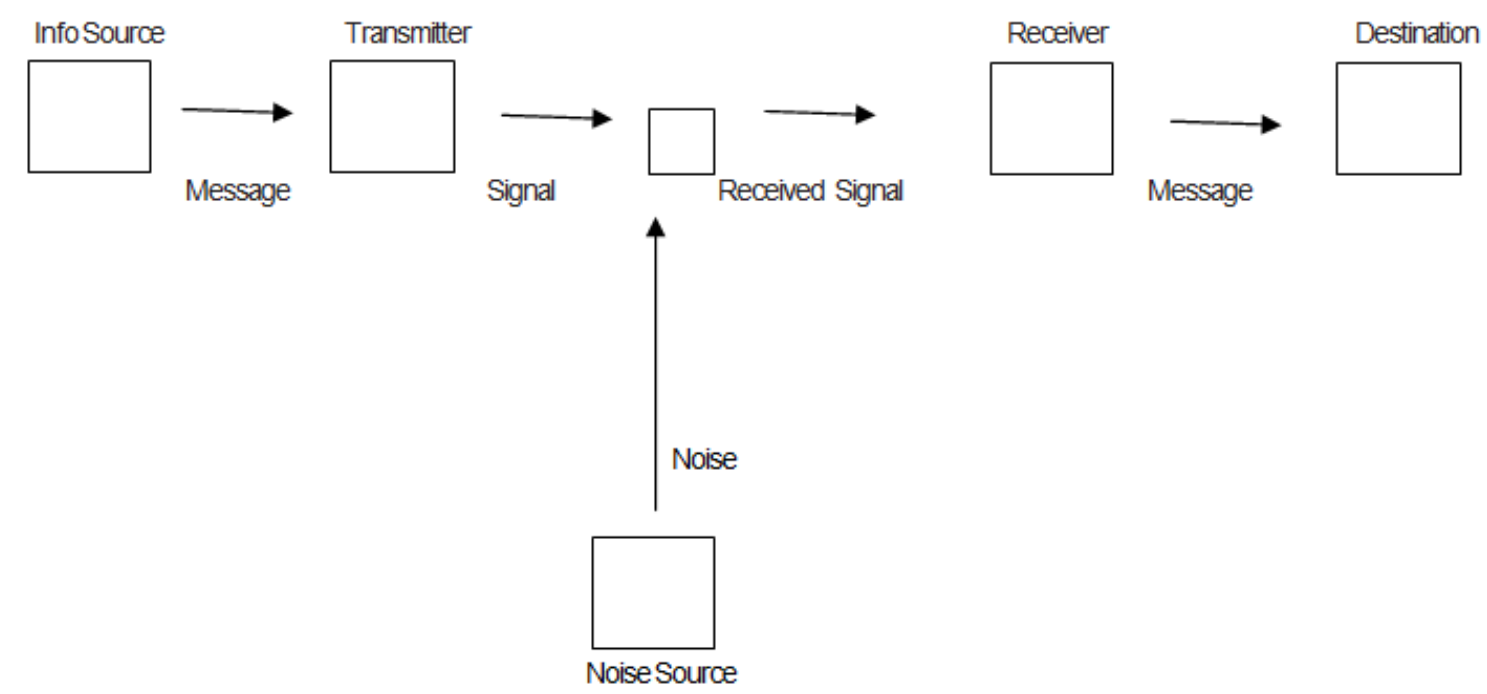

\section{REFERENCES}

[1] Oxford, R.L. (1990). Language learning strategies: What every teacher should know. New York: NewburyHouse.

[2] Chamot, U. A., \& El-Dinary, B. P. (1999). Children's learning strategies in language immersion classrooms. The Modern Language Journal, 83 (3), 319-338

[3] http://nflrc.hawaii.edu/networks/TR25/TR25-3.pdf

[4] Dubberly, H., \& Pangaro, P. (2009, May 1). What is conversation?: How can we design for effective conversation [Scholarly project]. Retrieved April 15, 2017, from what-is-conversation.html (p.1)

[5] Dubberly, H., \& Pangaro, P. (2009, May 1). What is conversation?: How can we design for effective conversation [Scholarly project]. Retrieved April 15, 2017, from what-is-conversation.html (p.2)

[6] Friesen, P. R. (n.d.). Retrieved April 14, 2017, from http://makingconversationworkforyou.com/

[7] Dubberly, H., \& Pangaro, P. (2009, May 1). What is conversation?: How can we design for effective conversation [Scholarly project]. Retrieved April 15, 2017, from what-is-conversation.html (p.3)

[8] Shai, M. A. (2016). Integrating or Segregating the Language Skills in EFL classroom? That's the Question! Retrieved April 14, 2017, from https://www.academia.edu/21732129/Integrati ng_or_Segregating_the_Language_Skills_in_EFL_ classroom_Thats_the_Question_academia.edu

[9] http://www.daggerpress.com/2014/07/29/number-of-teachersleaving-harford-county-public-schools-jumps-36-over-past-3years/ 